\title{
Language Learning Strategies Based On Gender
}

\author{
Farida Ariyani \\ Language Education, Faculty of Education, Universitas Lampung, Indonesia \\ Nurlaksana Eko Rusminto \\ Language Education, Faculty of Education, Universitas Lampung, Indonesia \\ Ag. Bambang Setiyadi \\ Language Education, Faculty of Education, Universitas Lampung, Indonesia
}

\begin{abstract}
Gender as an individual characteristic has been proved to affect the use of strategies in learning a foreign language but how gender affects the use of strategies in learning a local language where the people in the community speak a national language is not explored yet. Some studies show that female students employed language learning strategies more often than male students (Oxford \& Nyikos, 1989; Awang Hashim \& Syed Sahil, 1994; Green and Oxford, 1995; Dreyer \& Oxford, 1999). The present study was aimed to identify how gender affects the use of strategies in learning a local language in the environment where people in the country have a national language. A Non-probability sampling was used to collect data. With the Cronbach Alphas ranging from .79 to 82, mean scores of the use of language learning strategies the male and female students reported using were compared. In the present study it was found that metacognitive strategies were the strategies mostly used by female students and cognitive strategeis were the strategies mostly used by male students. This means that male students are likely to be more dependent on memorization than female students. Cognitive strategies which are characterized at least with memorization or rote learning in the present study tend to be used by male students.
\end{abstract}

Index Terms - cognitive strategies, gender, language learning strategies, local language, metacognitive strategies, social strategies

\section{INTRODUCTION}

Human beings have the capacity to acquire another language. The acquisition process cannot be separated from the types of input available in their surroundings. Within the scope of SLA research, input data have most typically comprised recurrent linguistic features of speech and, in some studies, written texts, addressed to learners, as well as the function in assisting learners' comprehension, supplying feedback on their imprecisions, and guiding them toward more accurate production (Pica, 1991, p. 187). The input available to learners not necessarily becomes comprehensible for them to process. It involves the so-called input processing (Van Patten \& Sanz, 1995, pp. 170-171). In this process, input is converted into intake. From this process learners must still develop an acquired system; it means that not all intake is automatically fed into the acquired system in Krashen sense, and there are still some other processes that learners have to do before input becomes output such as the conversion of input to intake and encoding linguistically. Because it deals with individual processes, many variables are automatically involved in the process and different individuals will use different processes. Even though they receive the same input, at the end of the learning process, they may have different levels of second language quality in their output. The differences in output cannot be separated from the role of individual differences.

Second (foreign) language learners can differ in many ways. Skehan (1989, p. 4) states some of the individual differences of learners include age, intelligence, aptitude, motivation, attitude, personality, and cognitive styles while in the process of learning the learners may differ in strategies. A study by Ehrman (1996) indicates that individual differences correlated with language learning. In her study individual differences in motivation proves to be significantly correlated with language learning. Individual variables, such as bilinguals/multilingualism (Nayak et al., 1990 \& Klein, 1995), attitude, gender (Oxford \& Nyikos, 1989; Green \& Oxford, 1995), ethnicity (Politzer \& McGroarty, 1985; Grainger, 1997; LoCastro, 1994), proficiency level (O'Malley, 1985; Green \& Oxford, 1995) and motivation (Setiyadi, Sukirlan \& Mahpul, 2016) have been investigated in relation to language learning strategies.

Related to gender, the result of the study by Green and Oxford (1995) shows that female students used 14 strategies more frequently than did male students. The the study has uncovered important information on gender-related language strategies. The present study continued to explore different strategies used by female and male students and relate the strategies in learning a local language in the context where a country has a national language.

Some studies show that female students employed language learning strategies more often than male students (Awang Hashim \& Syed Sahil, 1994: Dreyer \& Oxford, 1999; Green \& Oxford, 1995; Oxford \& Nyikos, 1989). Oxford and Nyikos (1989) also describe that gender differences in using conversational input elicitation strategies or reflecting strategies. In their study, conducted in Puerto Rico, Green and Oxford (1995) show that women performed more 
frequently than did men the six categories of SILL: memory, cognitive, compensation, metacognitive, affective and social strategies. Another study on the different uses of language learning based on gender was conducted by Graham and Rees (1995). Their study, which involved children, showed that in learning a language, female and male students prefer different learning strategies but their study did not investigate different amount of strategy use between the two groups of students. Their study also suggests that anxiety related to peer-group judgement is more common among female students, although they acknowledge that their finding contradicts the findings of other studies that suggest boys are reluctant to speak out in the public arena.

Many studies have been conducted to relate second /foreign language learning with individual characteristics (Jacobsen \& Imhoof, 1974; Bialystok \& Frohlich, 1978; Wen \& Johnson, 1997), but only a few associated individual variables with language learning strategies. Awang Hashim and Syed Sahil (1994) also report that gender affects the uses of language learning strategies. The result of their study, which used Oxford's SILL as a strategy measure, showed that female students used affective strategies more often. Their study was inspired by that Oxford and Nyikos (1989). They also suggest the same reason why female students employed language learning strategies more frequently than male students in the Malaysian context. However, the trend towards female students' greater use of metacognitive and deep level strategies and less use of surface level strategies in this study would need a different explanation.

Gender as an individual characteristic has been proved to affect the use of strategies in learning a foreign language but how gender affects the use of strategies in learning a local language where the people in the community speak an national language is not explored yet. The present study is aimed to identify how gender affects the use of strategies in learning a local language in the environment where people in the country have a national language.

\section{Methodology}

A Non-probability sampling was used to collect data. The population of the present study were learners who have been learning a local language at school and the subjects came from different school. In Indonesia the students generally speak Indonesian language as the national language. The students were briefed before the data were collected and confidentiality was confirmed. They could use as much time to complete the questionnaire. The reason of choosing the subjects was that they spoke the national language at home and learned a local language at school.

The data in the present study were collected through a questionnaire, which has been modified from Setiyadi (2001; 2004). This questionnaire, which is called Language Learning Strategy Questionnaire (LLSQ), consists of 80 items. In the questionnaire of the language strategy use, language learners were provided with statements with five possible answers which were arranged in an ordinal variable. The scores of the choices are 1 for never on and 5 for always (see Appendix). The questionnaire was given in in the mother tounge of the learners. The LLSQ includes 4 categories of learning strategies: speaking strategies, listening strategies, reading strategies and writing strategies and each category consists of 20 items. In total the LLSQ has 80 items and each category has learning strategies that are grouped under cognitive, metacognitive and social strategies.

\section{RESUlT AND DisCUSSION}

Cronbach Alpha coefficient for each scale was computed. As shown on Table 1, the scales of the scales were internally consistent; the Cronbach Alphas show satisfactory to good reliability, ranging from .79 to 82 . Table 2 provides evidence that the items of the questionnaire had high correlation with their constructs so that the items developed in the present study was considered valid. In general, the items had high correlation with the constructs of each category so that the items of the questionnaire was considered valid, as shown on Table 2. Therefore, all of the criteria of the constructs were met in the present study.

TABLE 1:

RELIABILITY OF THE MEASURES

\begin{tabular}{|l|l|l|}
\hline Scales & Items & Cronbach's alpha \\
\hline Listening Strategies & 20 items & .79 \\
\hline Speaking Strategies & 20 items & .80 \\
\hline Reading Strategies & 20 items & .82 \\
\hline Writing Strategies & 20 items & .70 \\
\hline
\end{tabular}

TABLE 2:

VALIDITY OF EACH ITEM WITH THE CONSTRUSTS

\begin{tabular}{|l|l|}
\hline Constructs & Item number and the validity \\
\hline Listening & $1) 0,739,2) 0,728,3) 0,720,4) 0,741,5) 0,789,6) 0,773,7) 0,719,8) 0,734,9) 0,738,10) 0,711,11) 0,741$, \\
Strategies & $12) 0,764,13) 0,736,14) 0,815,15) 0,717,16) 0,751,17) 0,725,18) 0,719,19) 0,743,20) 0,706$ \\
\hline Speaking Strategies & $1) 0,639,2) 0,721,3) 0,770,4) 0,641,5) 0,719,6) 0,721,7) 0,732,8) 0,744,9) 0,722,10) 0,721,11) 0,733$, \\
& $12) 0,732,13) 0,743,14) 0,811,15) 0,722,16) 0,741,17) 0,735,18) 0,729,19) 0,721,20) 0,716$ \\
\hline Reading Strategies & $1) 0,739,2) 0,733,3) 0,670,4) 0,711,5) 0,722,6) 0,735,7) 0,755,8) 0,741,9) 0,754,10) 0,763,11) 0,737$, \\
& $12) 0,744,13) 0,757,14) 0,711,15) 0,732,16) 0,723,17) 0,744,18) 0,781,19) 0,735,20) 0,718$ \\
\hline Writing Strategies & $1) 0,745,2) 0,744,3) 0,723,4) 0,741,5) 0,722,6) 0,741,7) 0,737,8) 0,731,9) 0,782,10) 0,777,11) 0,751$, \\
& $12) 0,732,13) 0,754,14) 0,751,15) 0,777,16) 0,761,17) 0,735,18) 0,726,19) 0,722,20) 0,711$ \\
\hline
\end{tabular}


TABLE 3:

MEAN SCORES OF LEARNING STRATEGIES BY GENDER

\begin{tabular}{|l|l|l|l|}
\hline & Metacognitive strategies & Cognitive strategies & Social strategies \\
\hline Female & 3.63 & 3.11 & 3.18 \\
\hline SD & .63 & .46 & .48 \\
\hline Male & 3.31 & 3.52 & 3.05 \\
\hline SD & .66 & .51 & .61 \\
\hline
\end{tabular}

Note: $\mathrm{SD}=$ standard deviation

For the purpose of comparison between the strategies used by female and male learners, mean scores of the use of language learning strategies the students reported using were compared. Table 3 provides empirical support for no significant differences between female and male students' use of language learning strategies. In general there was a trend that female students employed language learning strategies more often than did male students. The mean score of metacognitive strategeis by female students was higher than the mean score of the same strategies by male students. Male sudents used cognitive strategies more often than female students and the mean score of cognitive strategies of male students was the only mean score which was higher than female students.

\section{DISCUSSION}

In the present study it was found that metacognitive strategies were the strategies mostly used by female students and cognitive strategeis were the strategies mostly used by male students. The use of social straegeis of two groups was relatively equal. Even though female students and male students used the three groups of strategies in different frequencies, the two groups did not show that the differences in using the strategies were not significant. That there was no significant difference between male and female students in using strategies in the present study is in line with the findings in a study conducted by El-Dib (2014), which was conducted in Kuwait. The findings of El-Dib's (2014) study reveal that female students use more cognitive strategies more than male students do even though his study was also not in line with his previous study (1999), which provides contradictory evidence that there was no significant difference in using learning strategies between male and female students. He also suggests that the use of learning strategies between male and feemale students was cultural context.

This finding of the present study supports to some extent those of previous studies (Oxford \& Nyikos, 1989; Green \& Oxford, 1995) that female students employed language learning strategies more often than male students (see also Dreyer \& Oxford, 1999. However, the findings of the present study was not in line with a study by Park (2011). The study which was conducted in Korea showed that male students more learning strategies than female students, espesially in using memory strategies of SILL (Park (2011).

The extended model of student learning developed in a study by Meyer, Dunne and Richardson (1994) may be used to contextualize the differences between male and female students in using language learning strategies. They suggest that competitiveness, versatility and a dependence upon memorization are of less importance in characterizing individual differences among female students than they are in characterizing individual differences among male students. This means that male students are likely to be more dependent on memorization than female students. Cognitive strategies which are characterized at least with memorization or rote learning in the present study tend to be used by male students. However, the greater likelihood of female students to use metacognitive may be hard to explain although a notion suggested by Graham and Rees (1995, p.18) may be relevant. Their study indicated that female students feared a negative evaluation of their classmates, and performance in oral work was bound up with how one might be viewed by others as a person, rather than just from the point of view of language proficiency. Their fear to be evaluated by others seems to produce self-monitoring, self-evaluation and self-correction. These strategies are classified under metacognitive strateies in the present study.

\section{CONCLUSION AND SUGGESTION}

Gender as an individual characteristic may affect the use of strategies in learning a local language. In the present study male students rely more on cognitive strategies while female students use metacognitive strategeis more in learning a local language. It is suggested that language teacher may provide their students with learning opportunities so that female and male students may use language learning strategies differently which are appropriate with their gender characterics. Hopefully, by providing students with a variety of learning oppotunities, the Lampungese students can produce greater frequency of learning strategy use which contributes to the success of learning a local language.

\section{APPENDIX. LANGUAGE LEARNING STRATEGy QUESTIONNAIRE}

Directions

You will find some statements about learning Lampungese. On the separate worksheet, write the response (1, 2, 3, 4, or 5) that tells HOW TRUE OF YOU THE STATEMENT IS.

1. Never or almost never true of me

2. Usually not true of me 
3. Somewhat true of me

4. Usually true of me

5. Always or almost always true of me

In Listening

1. I try to guess what somebody is saying by using grammatical rules.

2. I learn Lampungese by watching Lampungese TV programs.

3. I learn Lampungese by listening to Lampungese songs or other listening scripts.

4. I try to understand what somebody is saying by translating into Indonesian.

5. I draw an image or picture of the word in order to remember the word.

6 . I connect the pronunciation of the word with the Indonesian word which has a similar sound.

7. I concentrate on the grammar rather than on the communication.

8. I try to understand the idea by referring to previous experiences I have had.

9. I try to guess by using a word (s) that is familiar to me.

10. In Listening, I take notes to remember ideas.

11. I try to understand every individual word to understand the passage.

12. I listen to what I say to practice my listening skill.

13. Before practicing my listening skill, I prepare a topic, pronunciation or grammatical rules which give me the greatest trouble.

14. I try to remember a sentence(s) spoken face-to-face or on cassettes and analyze them by myself.

15. After a listening practice, I check and recheck my understanding.

16. I correct the mistakes that I produce orally.

17. I try to be aware of which sounds give the greatest trouble. In this way I can pay special attention to them while I listen and practice.

18. If I cannot understand what somebody is saying, I ask him/her to slow down or say it again.

19. Listening to what somebody is saying improves my listening skill.

20. In a group discussion, my listening skill is improved.

In Speaking

1. I use rhymes to remember new Lampungese words.

2. I try to remember new Lampungese words by pronouncing them.

3. I speak a word or a sentence several times to remember it.

4. I try to learn a new pattern by making a sentence orally.

5. I try to translate Indonesian sentences into Lampungese sentences and produce them orally.

6. I try to remember what the Lampungese word equivalent to Indonesian word is.

7. I tape record the sentences I produce.

8. I mix Indonesian words and Lampungese words if I do not know the Lampungese words.

9. I put words into rules that I know in speaking.

10. Before I respond orally to questions, I write out the answers.

11. I try to correct my mistakes that I produce orally.

12. I try to speak with myself to improve my speaking.

13. I try to evaluate my utterances after speaking.

14. I notice my Lampungese mistakes, and use that information to help me do better.

15. I prepare a topic or grammatical rules in speaking practice.

16. I ask somebody to correct me when I talk.

17. I practice speaking with my friends or my teachers.

18. I practice Lampungese with native speakers.

19. I ask questions in Lampungese.

20. If I cannot think during a conversation in Lampungese, I use gestures.

In Reading

1. To understand unfamiliar Lampungese words while I am reading, I guess from available clues.

2. I learn Lampungese by reading Lampungese books or magazines.

3. I connect the spellings of Lampungese words with similar Indonesian words to understand the meanings.

4. I try to understand sentences by analysing their patterns.

5. I try to translate word for word.

6. I try to understand the passage by using my general knowledge and experience.

7. I use the key words to understand the whole ideas.

8. I read the passage aloud.

9. I take notes to remember the ideas.

10. While I read a text, I try to anticipate the story line.

11. I read a text more for ideas than words.

12. I correct my mistakes by rereading the text. 
13. I choose a topic or certain materials for my practice.

14. I check and recheck my understanding after reading a passage.

15. If I cannot understand a reading passage, I try to analyse what difficulty I actually have.

16. In reading, I pick out key words and repeat them to myself.

17. I try to be aware of which words or grammar rules give me the greatest trouble. In this way I can pay special attention to them while I read and practice.

18. I discuss reading passages with my friends.

19. If I do not understand the content of a reading passage, I ask my friends or my teachers for help.

20. I improve my reading skill by reading letters from my friends.

In Writing

1. If I do not know how to express my ideas in Lampungese while writing, I keep writing using certain rules that I know.

2. I write what I am thinking about.

3. I keep a diary.

4. I try to remember the meanings of words or the patterns by writing them.

5. I write sentences to apply certain rules.

6. I try to translate word for word.

7. I mix Indonesian words and Lampungese words in writing.

8. I write the main ideas first as a guideline.

9. I use Indonesian words if I do not know the Lampungese words.

10. I use Indonesian patterns to keep writing in Lampungese.

11. I consult a dictionary to find out the meanings of words.

12. I write out new material over and over.

13. I try to memorize the meanings of words.

14. I rewrite my composition by correcting the mistakes that I notice.

15. I choose a topic to improve my writing skill.

16. I read my writing and correct the mistakes.

17. I try to be aware of which words or grammar rules give the greatest trouble, this way I can pay special attention to them while I write and practice.

18. I write a message to my friends in Lampungese for practice.

19. I write letters in Lampungese to my friends.

20. I ask my friends or my teachers to correct my writing.

\section{ACKNOWLEDGMENTS}

We would like to thank the students for helping to collect the data. The present study was financially supported by the Faculty of Education, Universitas Lampung, the Ministry of Research, Technology and Higher Education of Indonesia.

\section{REFERENCES}

[1] Awang Hashim, R \& S. Syed Sahil. (1994). Examining learners' language learning strategies. Singapore: RELC Journal 25. 2, $1-20$.

[2] Bialystok, E. (1981). The role of conscious strategies in second language proficiency. Modern Language Journal, 65, 24-35.

[3] Dreyer, C. \& R.L. Oxford. (1996). Learning strategies and other predictors of ESL proficiency among Afrikaans speakers in South Africa. In Rebecca L. Oxford (Ed.), Language Language Strategies in the World, 61 - 74. Honolulu: University of Hawaii.

[4] Ehrman, M. (1996). Understanding Second Language Learning Difficulties. Honolulu: University of Hawaii Press.

[5] El-Dib, M. A. (2014). Language learning strategies in Kuwait: links to gender, language Level, and culture in a hybrid Context. Foreign Language Annals 37.1, 85 - 95.

[6] Graham, S \& F. Rees. (1995). Gender differences in language learning: the question of control. Language Learning Journal 11, 18-19.

[7] Grainger, P. R. (1997). Language learning strategies for learners of Japanese: investigating ethnicity. Foreign Language Annals 30. 3, 378-385.

[8] Green John M. and R. Oxford. (1995). A closer look at learning strategies, L2 proficiency, and gender. TESOL Quarterly 29.2, 261-297.

[9] Jacobsen, M \& M. Imhoof. (1974). Predicting success in learning second language. The Modern Language Journal, LVIII. 5-6, 329-366.

[10] Klein, E. C. (1995). Second versus third language acquisition: Is there a difference? Language Learning, September 45.3, 419465.

[11] LoCastro, V. (1994). Learning strategies and learning environments. TESOL Quarterly 28.2, 409-414.

[12] Meyer, J.H.F., T.T. Dunne, \& J.T.E., Richardson. (1994). A gender comparison of contextualised study behavior in higher education. Higher Education 27, 469-485. Netherlands: Kluwer Academic Publishers. 
[13] Nayak, N., N. Hansen, N. Krueger \& B. McLaughlin. (1990). Language -learning strategies in monolingual and multilingual adults. Language Learning, 40.2, 221-244.

[14] O’Malley, M. (1985). Learning strategies used by beginning and intermediate ESL students. Language Learning 35.1, 21-44.

[15] Oxford, R. \& M. Nyikos. (1989). Variables affecting choice of language learning strategies by university students. The Modern Language Journal 73. iii, 291-300.

[16] Park, G. (2011). Beyond the mean differences of the SILL by gender: differential item functioning. The Journal of Asia TEFL 8. 4, 75-203.

[17] Pica, T. (1991). Input as a theoretical and research construct. IRAL XXIX. 3, 185-193.

[18] Politzer, R. L. \& M. McGroarty. (1985). An exploratory study of learning behaviors and their relationship to gains in linguistics and communicative competence. TESOL19.1, 103-123.

[19] Setiyadi, A. B. (2001). Language Learning Strategies: Classification and Pedagogical Implication. TEFLIN Journal 12.1 , 15 28.

[20] Setiyadi, A. B. (2004). Redesigring Language Learning Strategy Classification. TEFLIN Journal, 15. 2,230 - 245.

[21] Setiyadi, A. B., M. Sukirlan \& Mahpul. (2016). How Successful Learners Employ Learning Strategies in an EFLSetting in the Indonesian Context. English Language Teaching 9.8, $28-38$.

[22] Skehan, P. (1989). Individual Differences in Second Language Learning. London: Hoddor and Stoughton Limited.

[23] Van Patten, B \& C. Sanz. (1995). From input to output: processing communication and communicative tasks. In Fred R. Eckman (Eds.), Second Language Acquistion Theory and Pedagogy, 169-185. Mahwah, New Jersey: Lawrence Erlbaum Associates, Publishers.

Farida Ariyani is a lecturer in Lampungese studies at the Department of Language Education. She has taught Lampungese courses at the Faculty of Education, Lampung University, Indonesia. Her research interests include second language acquisition, communication strategies as well as intercultural communication.

Nurlaksana Eko Rusminto is a lecturer in the Department of Language Education, Faculty of Education, Lampung University. His researches mainly include language teaching and linguistics. He has published several books and papers.

Ag. Bambang Setiyadi is a lecturer presenting courses in language teaching methodology and research methodology at the Department of English Language of Lampung University, Indonesia. He has presented and published nationally and internationally on issues related to language teaching and learning. 